\title{
BMJ Open Anastomotic leakage after intrathoracic versus cervical oesophagogastric anastomosis for oesophageal carcinoma in Chinese population: a retrospective cohort study
}

\author{
Yin-jiang Liu, ${ }^{1}$ Jun Fan, ${ }^{2}$ Huang-he He, ${ }^{3}$ Shu-sheng Zhu, ${ }^{1}$ Qiu-lan Chen, ${ }^{1}$ \\ Rong-hua Cao ${ }^{1}$
}

To cite: Liu Y, Fan J, He H, et al. Anastomotic leakage after intrathoracic versus cervical oesophagogastric anastomosis for oesophageal carcinoma in Chinese population: a retrospective cohort study. BMJ Open 2018;8:e21025. doi:10.1136/ bmjopen-2017-021025

\section{- Prepublication history for} this paper is available online. To view these files, please visit the journal online (http://dx.doi. org/10.1136/bmjopen-2017021025).

Y-L and JF contributed equally.

Received 8 December 2017

Revised 12 June 2018

Accepted 23 July 2018

Check for updates

(C) Author(s) (or their employer(s)) 2018. Re-use permitted under CC BY-NC. No commercial re-use. See rights and permissions. Published by BMJ.

${ }^{1}$ Department of Thoracic Surgery, Taizhou City Hospital of Traditional Chinese Medicine, Taizhou, China

${ }^{2}$ Department of Thoracic Surgery, The First Affiliated Hospital of Nanjing Medical University, Nanjing, China ${ }^{3}$ Department of Thoracic Surgery, The First Affiliated Hospital of Guangzhou Medical University, Guangzhou, China

Correspondence to

Dr Shu-sheng Zhu;

drsszhus@sina.com

\section{ABSTRACT}

Objective To investigate the characteristics and predictors for anastomotic leakage after oesophagectomy for oesophageal carcinoma from the perspective of anastomotic level.

Design Retrospective cohort study.

Settings A single tertiary medical centre in China. Participants From January 2010 to December 2016, all patients with oesophageal cancer of the distal oesophagus or gastro-oesophageal junction undergoing elective oesophagectomy with a curative intent for oesophageal carcinoma with intrathoracic oesophagogastric anastomosis (IOA) versus cervical oesophagogastric anastomosis (COA) were included. We investigated anastomotic level and perioperative confounding factors as potential risk factors for postoperative leakage by univariate and multivariate logistic regression.

Primary outcome measures The primary outcome was the odds of anastomotic leakage by different confounding factors. Secondary outcome was the association of IOA versus COA with other postoperative outcomes.

Results of 458 patients included, 126 underwent cervical anastomosis and 332 underwent intrathoracic anastomosis. Anastomotic leakage developed in 55 patients (12.0\%), with no statistical differences between COA and IOA (16.6\% vs $10.2 \% ; p=0.058$ ). Multivariable analysis identified active diabetes mellitus (OR 2.001, $p=0.047$ ), surgical procedure (open: reference; minimally invasive: OR 1.770, $p=0.049$ ) and anastomotic method (semimechanical: reference; stapled: OR 1.821; handsewn: OR 2.271, $p=0.048)$ rather than anastomotic level (IOA: reference; COA: OR 1.622, $p=0.110$ ) were independent predictors of leakage.

Conclusions Surgical and anastomotic techniques rather than the level of anastomotic site were independent predictors of postoperative anastomotic leakage in patients undergoing oesophageal cancer surgery.

\section{INTRODUCTION}

Oesophageal carcinoma is one of the most common malignant gastrointestinal tumours in China, carrying a high mortality risk if not
Strengths and limitations of this study

- This is a retrospective cohort study using real-world clinical data to evaluate the characteristics and risk factors for anastomotic leakage after oesophagectomy from the perspective of the level of anastomosis.

- Detailed perioperative parameters allow us to better elucidate the risk factors for predicting anastomotic leakage and to address the impact of the level of anastomosis on other surgical outcomes.

- The retrospective collection of clinical factors is subject to recall bias and other biases.

treated immediately and properly. ${ }^{1}$ Despite extensive advances in the treatment strategies, oesophagectomy remains the standard therapy for curable patients with oesophageal carcinoma. ${ }^{2}$ However, anastomotic sites are prone to leakage with a reported incidence ranging from $5 \%$ to up to $30 \%,{ }^{3}$ which leads the cause of morbidity and mortality in patients undergoing surgery for oesophageal cancer. ${ }^{2}$ As a serious complication, anastomotic leakage accounts for up to $20 \%$ of readmission ${ }^{4}$ and increases the risk of recurrence and reduces long-term survival. ${ }^{5}$

At present, cervical oesophagogastric anastomoses (COA) and intrathoracic oesophagogastric anastomoses (IOA) have enjoyed widespread adoption and acceptance in the maintenance of the anatomical and functional integrity of gastrointestinal tract with esophagectomy. Recently, there is a growing focus on the potential impacts of anastomotic level on anastomotic leakage. Some studies point outed the association of IOA with a low leakage rate but potentially high morbidity and mortality, and the association of COA with a higher leakage rate but more manageable complications. ${ }^{56}$ However, there has 
been no consensus yet on these findings due to the diversity of sample size and study design. Although diabetes has been identified as predictors of leakage, other preoperative risk factors for leakage remains controversial, ${ }^{7-9}$ and knowledge is little regarding the effect of operative factors on the risk of anastomotic leakage after oesophagectomy.

The aim of our study was to investigate the consequences of intrathoracic versus cervical anastomosis after oesophagectomy and identify predisposing perioperative risk factors for development of leakage following oesophageal cancer surgery in a large number of patients, which contributes to providing important information for better selection of patients and to allowing the surgeon to create a patient-tailored approach for appropriate decision-making.

\section{MATERIALS AND METHODS}

\section{Study design, setting and participants}

Between 1 January 2010 and 31 December 2016, all patients with oesophageal cancer of the distal oesophagus or gastro-oesophageal junction undergoing elective esophagectomy with a curative intent for oesophageal carcinoma with COA and with IOA were included and analysed retrospectively at Taizhou City Hospital of Traditional Chinese Medicine. All patients provided written informed consent.

\section{Patient and public involvement}

Patients and public were not involved in this study.

\section{Surgical procedure}

The standard operation consisted of en bloc oesophagectomy with two-field or three-field lymph node dissection via conventional thoracotomy or video-assisted thoracic surgery, gastric tube reconstruction and final oesophagogastric anastomosis using the stomach in all patients as described previously. ${ }^{1011}$ All patients underwent laparoscopic or open gastric mobilisation. Laparoscopic mobilisation was the same as in the open approach, with the stomach mobilised on the greater curvature of stomach and right gastroepiploic arcades using ultrasonic shears. Both procedures included partial division of the lesser curvature of the stomach with a linear stapler to create a gastric tube. ${ }^{12}$

The anastomosis was usually established on the posterior wall of the gastric tube by a mechanical procedure using a circular or liner stapler, hand-sewn procedure or semimechanical procedure, in an end-to-end, end-to-side or side-to-side fashion if appropriate. Anastomosis was fashioned manually in two layers using a running inner layer suture and an interrupted outer layer. Cervical anastomosis was done at the level of thyroid on the interior sternocleidomastoid muscle of the left neck, and intrathoracic anastomosis was done in the upper chest or around the level of azygos arch depending on the location of tumour. The length of the remnant cervical oesophagus was typically $2-4 \mathrm{~cm} .{ }^{13}$ Both cervical and intrathoracic anastomosis was performed through the oesophageal bed in the posterior mediastinum. Pyloroplasty was left to the surgeon's discretion. Cervical lymph node dissection was selectively performed on the basis of preoperative ultrasonic, physical and radiological examinations.

Specific surgical approaches were performed mainly based on the clinical staging, pathological anatomy and biological characteristics. Besides, the conditions of all patients and the most suitable surgical approach that could be performed were discussed at a joint medical and surgical thoracic conference, while taking into consideration the willingness of patients and local experience of surgeons and the surgeons' preference.

\section{Data collection and outcome measures}

Data of the patients collected included the demographics, preoperative risk factors, intraoperative data in-hospital, 30 day and short-term conditions. Variables in the study were defined according to the Society of Thoracic Surgeons database. Carcinoma of oesophagus was characterised according to the tumour node metastasis classification system of the American Joint Committee for Cancer Staging (seventh edition). ${ }^{14}$ Primary outcomes were the rate of anastomotic leakage, operative morbidity, and operative mortality. In brief, the definition and classification of anastomotic leakage as well as other adverse events was same as described previously, ${ }^{15}$ according to the Esophagectomy Complications Consensus Group (ECCG) ${ }^{16}$ Taking into account the integrative assessment of radiographic examination, clinical sign and symptom and therapeutic schemes, we define and quantise the patterns and magnitude of dysphagia, dumping and regurgitation. The leak-related reoperation was defined as the incidence of reoperations mainly caused by leakage within 30 days after surgery.

\section{Statistical analysis}

Continuous variables were reported as means \pm SD and two-sample t-test or Mann-Whitney U-test were used to compare groups in univariate analysis. Categorical variables were reported as proportions and Pearson's $\chi^{2}$ test was used to compare groups in univariate analysis. Univariate analyses were performed to determine associations of clinical and pathological variables with overall anastomotic leak, major leak and stricture as endpoints. Those variables with $\mathrm{p}<0.25$ from univariate analyses were entered into multivariable logistic regression analyses. Backward stepwise elimination (using highest $p$ value as an elimination criterion) was used to derive the final multivariable logistic regression models to determine an adjusted effect size of variables on outcome. The results of multivariable analyses were expressed as OR with a $95 \% \mathrm{CI}$ and $\mathrm{p}$ value. A value of $\mathrm{p}<0.05$ was considered significant. All statistical analyses were performed using Stata V.14. 
Table 1 Comparison of clinical and pathological characteristics between groups

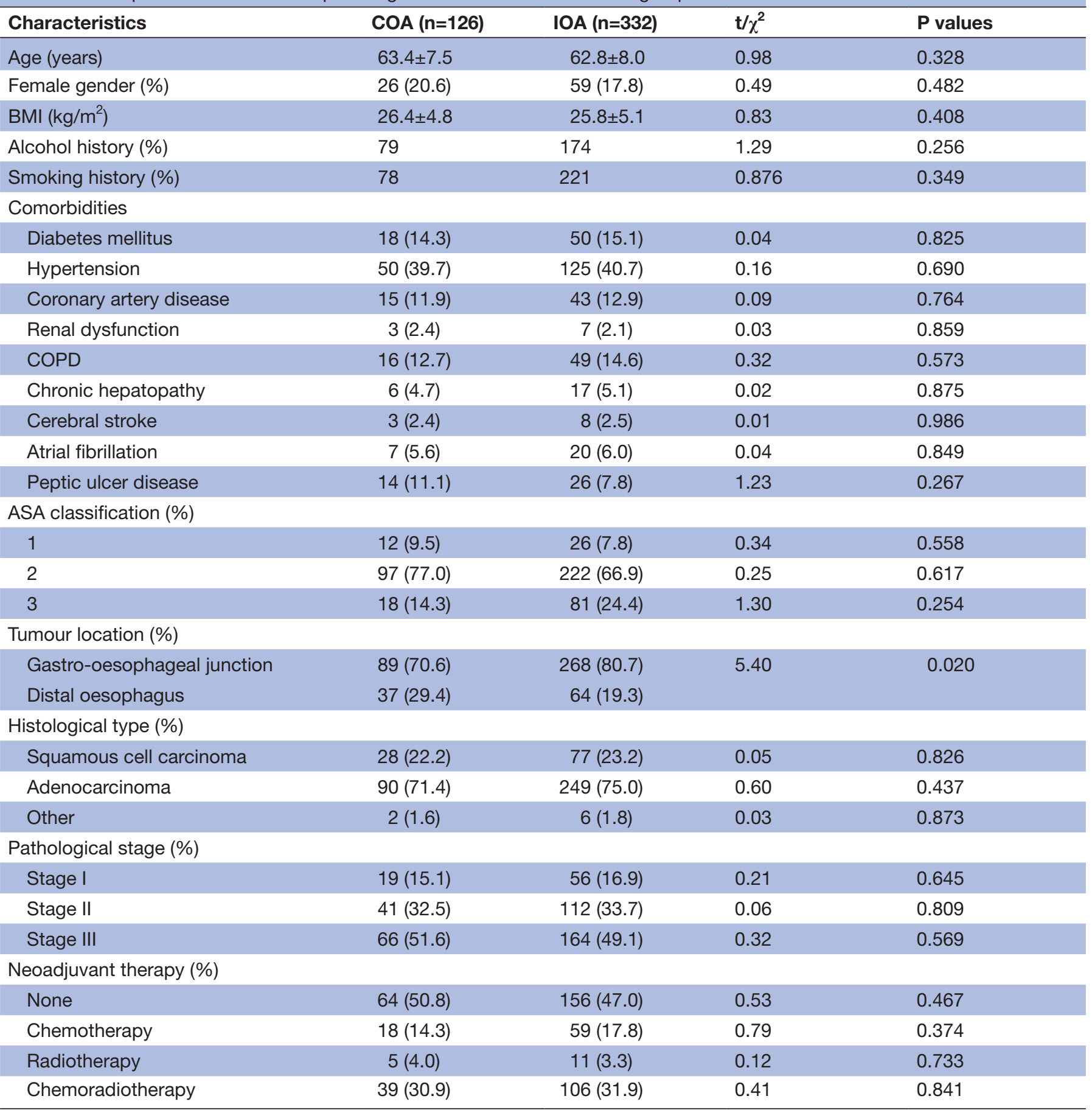

Values are expressed as mean \pm SD or number of patients $(n, \%)$.

$P$ value refers to comparison between patients with COA and IOA.

ASA, American Society of Anesthesiologists; BMI, body mass index; COA, cervical oesophagogastric anastomosis; COPD, chronic obstructive pulmonary disease; IOA, intrathoracic oesophagogastric anastomosis.

\section{RESULTS}

\section{Study population characteristics}

During the 6-year study period, a total of 584 patients undergoing oesophagectomy were identified through our medical records. Among them, 126 patients were excluded due to incomplete data, incorrect operation classification and uninterested population who underwent concomitant other cancer operations. Finally, 458 consecutive patients (360 men and 55 women) were included in the analysis. Their median age at the time of surgery was 61 years (range: 26-81 years). To compare the effect of level of anastomotic site on postoperative leakage, patients were divided into two groups (COA group: $\mathrm{n}=126(27.5 \%)$ and IOA group: $\mathrm{n}=332(72.5 \%))$. Of these patients, anastomotic leakage developed in 55 patients $(12.0 \%)$, among whom three returned to 
Table 2 Comparison of intraoperative and pathological characteristics between groups

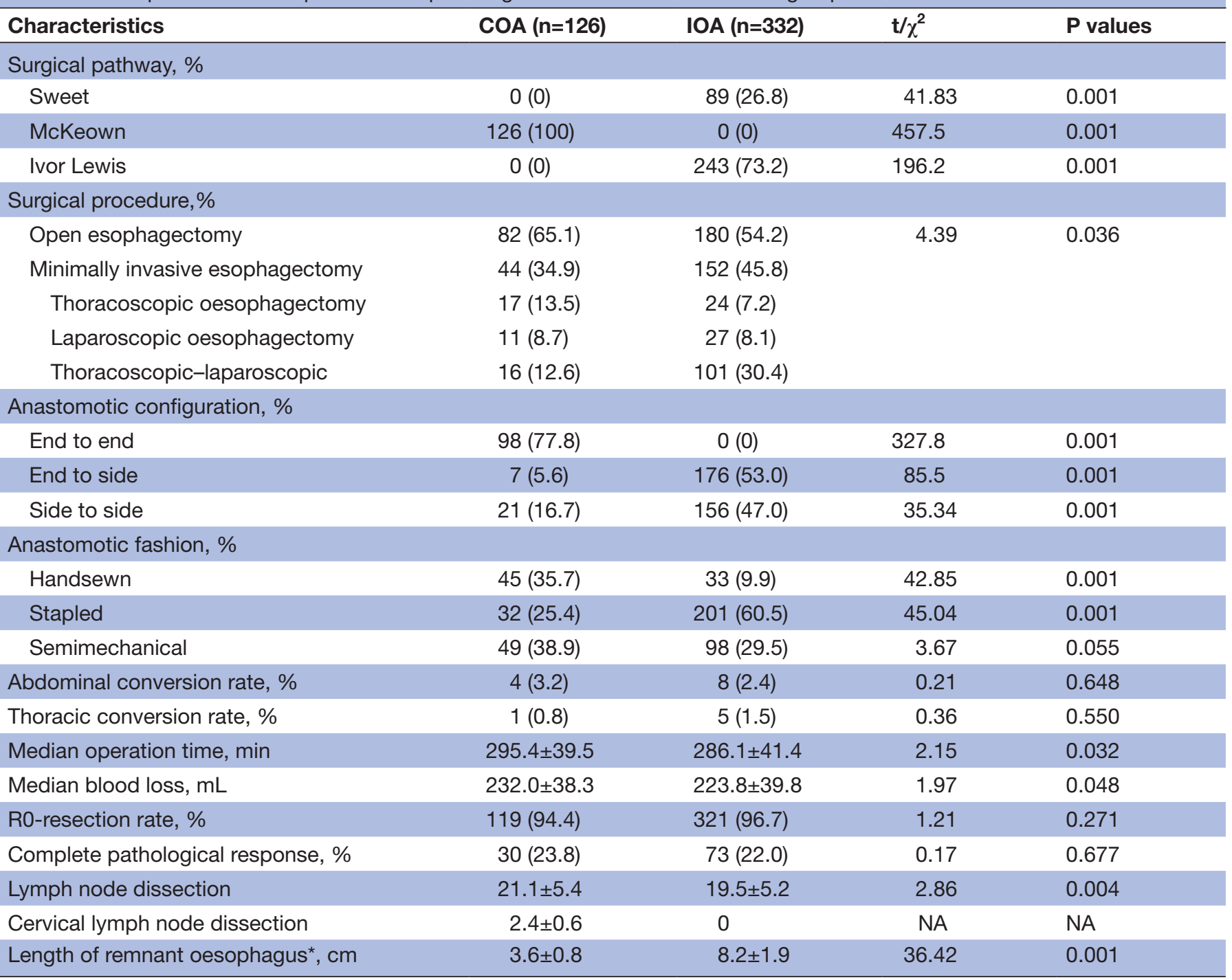

Values are expressed as mean \pm SD or number of patients $(n, \%)$.

$P$ values refers to comparison between patients with COA and IOA.

*The length of remnant oesophagus was measured on the radiological or endoscopic examinations postoperatively.

COA, cervical oesophagogastric anastomosis; IOA, intrathoracic oesophagogastric anastomosis; NA, not applicable.

the operating room for control of the leak and 51 were managed with conservative treatment (such as placing surgical drains, fasting, nutritional support, suction of gastric fluids and so on).

\section{Comparison of oesophagogastric anastomosis}

The baseline and clinical characteristics of patients according to oesophagogastric anastomotic level (COA or IOA) are presented in table 1 . The demographics, comorbidities, preoperative therapy, oncological characteristics and postoperative histological findings were comparable between both groups in all covariates with all p values $>0.05$ (table 1 ).

The intraoperative characteristics between the two groups are shown in table 2. The differences in abdominal conversion rate, thoracic conversion rate, R0-resection rate and complete pathological response and between groups were homogeneous with all $p$ values $>0.05$, except for surgical pathway, surgical procedure, anastomotic mode and anastomotic configuration, as well as operation time, blood loss and lymph nodes (table 2).

Postoperative morbidity and mortality results between groups are demonstrated in table 3. Overall, COA is associated with a higher leakage rate than IOA (16.6\% vs $10.2 \%)$, but the difference was statistically insignificant $(\mathrm{p}=0.058)$. IOA is superior to COA with regard to postoperative functional morbidity including recurrent laryngeal nerve injury, dysphagia, regurgitation, endoscopy for suspected anastomotic stricture and anastomotic stricture requiring dilatation. The incidence of thoracic complications, major adverse cardiovascular and cerebrovascular events and renal insufficiency were comparable between the groups. Regarding the secondary intervention, radiological reintervention was significantly more in the IOA group than in the COA group ( $\mathrm{p}=0.022$ ), but no statistical differences were found in 
Table 3 Comparison of postoperative morbidity and mortality between groups

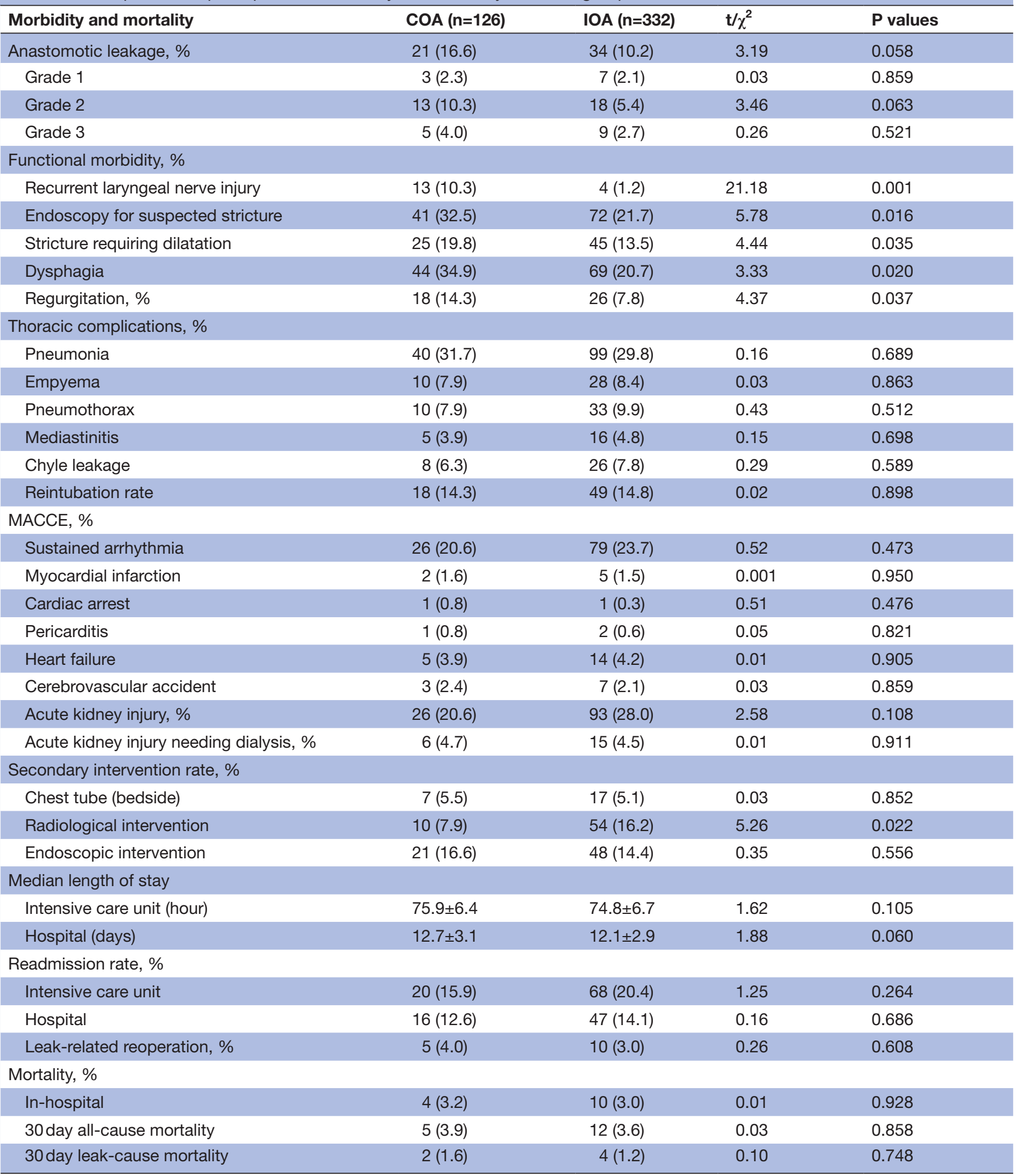

Values are expressed as mean \pm SD or number of patients $(n, \%)$.

$P$ value refers to comparison between patients with COA and IOA.

COA, cervical oesophagogastric anastomosis; IOA, intrathoracic oesophagogastric anastomosis; MACCE, major adverse cardiovascular and cerebrovascular events.

terms of chest tube and endoscopic intervention ( $p>0.05)$. No statistically significant differences were found between groups regarding the reintubation, hospital and intensive care unit length of stay, leak-related reoperation, in-hospital mortality and both 30 day all cause and leak-related mortality rates (table 3 ). 
Open access

Table 4 Comparison of preoperative and intraoperative characteristics in patients with and without AL

\begin{tabular}{|c|c|c|c|c|c|}
\hline Characteristics & Total (458) & $\begin{array}{l}\text { Without AL } \\
(n=403)\end{array}$ & $\begin{array}{l}\text { With AL } \\
(n=55)\end{array}$ & $t \chi^{2} / z$ & $P$ values \\
\hline Age $>60$ years & 293 & 251 & 42 & 4.15 & 0.042 \\
\hline Female gender & 85 & 71 & 14 & 1.96 & 0.161 \\
\hline Obesity & 122 & 102 & 20 & 4.25 & 0.039 \\
\hline Alcohol history & 253 & 225 & 38 & 3.47 & 0.062 \\
\hline Smoking history & 299 & 257 & 42 & 3.38 & 0.066 \\
\hline \multicolumn{6}{|l|}{ Comorbidities } \\
\hline Diabetes mellitus & 68 & 54 & 14 & 5.55 & 0.018 \\
\hline Hypertension & 175 & 150 & 25 & 1.39 & 0.239 \\
\hline Coronary artery disease & 58 & 47 & 11 & 3.04 & 0.081 \\
\hline Renal dysfunction & 10 & 8 & 2 & 0.62 & 0.432 \\
\hline COPD & 65 & 55 & 10 & 0.82 & 0.367 \\
\hline Chronic hepatopathy & 23 & 18 & 5 & 2.17 & 0.141 \\
\hline Cerebral stroke & 11 & 8 & 3 & 2.48 & 0.115 \\
\hline Atrial fibrillation & 27 & 23 & 6 & 2.20 & 0.138 \\
\hline Peptic ulcer disease & 40 & 32 & 8 & 2.64 & 0.098 \\
\hline \multicolumn{6}{|l|}{ ASA classification } \\
\hline $1 / 2 / 3$ & $38 / 319 / 99$ & $35 / 281 / 85$ & $3 / 38 / 14$ & 0.967 & 0.333 \\
\hline \multicolumn{6}{|l|}{ Tumour location } \\
\hline Gastro-oesophageal junction & 357 & 320 & 37 & 4.13 & 0.042 \\
\hline Distal oesophagus & 101 & 83 & 18 & & \\
\hline \multicolumn{6}{|l|}{ Histological type } \\
\hline SCC/Adenocarcinoma/Other & $105 / 345 / 8$ & $94 / 304 / 8$ & $11 / 44 / 0$ & 0.254 & 0.799 \\
\hline \multicolumn{6}{|l|}{ Pathological stage } \\
\hline Stage $1 / 2 / 3$ & $75 / 153 / 230$ & 68/138/199 & $7 / 17 / 31$ & 1.066 & 0.286 \\
\hline \multicolumn{6}{|l|}{ Neoadjuvant therapy } \\
\hline None/chemotherapy/radiotherapy/chemoradiotherapy & 220/77/16/145 & 194/68/14/127 & 26/9/2/18 & 0.165 & 0.869 \\
\hline \multicolumn{6}{|l|}{ Anastomotic level } \\
\hline COA/IOA & $126 / 332$ & $105 / 298$ & $21 / 34$ & 3.56 & 0.059 \\
\hline \multicolumn{6}{|l|}{ Surgical pathway } \\
\hline Sweet/Ivor Lewis/McKeown & $89 / 126 / 243$ & $83 / 113 / 206$ & $6 / 13 / 37$ & 2.221 & 0.026 \\
\hline \multicolumn{6}{|l|}{ Surgical procedure } \\
\hline Open & 262 & 238 & 24 & 4.69 & 0.030 \\
\hline Minimally invasive & 196 & 165 & 31 & & \\
\hline \multicolumn{6}{|l|}{ Anastomotic configuration } \\
\hline End to end/end to side/side to side & 98/183/177 & $87 / 161 / 155$ & $11 / 22 / 22$ & 0.282 & 0.778 \\
\hline \multicolumn{6}{|l|}{ Anastomotic mode } \\
\hline Handsewn/stapled/semimechanical & $78 / 233 / 147$ & $63 / 210 / 130$ & $15 / 23 / 17$ & 2.913 & 0.014 \\
\hline \multicolumn{6}{|l|}{ Stapled } \\
\hline Circular & 80 & 72 & 8 & 0.07 & 0.786 \\
\hline Linear & 153 & 138 & 15 & & \\
\hline
\end{tabular}

Values are expressed as mean $\pm S D$ or number of patients (n).

$P$ values refer to comparison between patients with $A L$ and without $A L$.

AL, anastomotic leakage; ASA, American Society of Anesthesiologist; COA, cervical oesophagogastric anastomosis; COPD, chronic obstructive pulmonary disease; IOA, intrathoracic oesophagogastric anastomosis; SCC, squamous cell carcinoma.

\section{Risk factors for anastomotic leakage}

The preoperative and operative variables between patients with and without anastomotic leakage are summarised in table 4 . We included all factors identified as $\mathrm{p}<0.1$ by univariate analysis (preoperative chemoradiotherapy, tumour location, tumour histology, surgical method, operation time and surgical procedure) and our interested clinical factors (the level of anastomotic site) 
Table 5 Logistic regression analysis identifying predictors for anastomotic leakage

\begin{tabular}{|c|c|c|c|c|c|c|}
\hline \multirow[b]{2}{*}{ Characteristics } & \multicolumn{3}{|c|}{ Univariate } & \multicolumn{3}{|c|}{ Multivariate } \\
\hline & OR & $95 \% \mathrm{Cl}$ & $P$ values & OR & $95 \% \mathrm{Cl}$ & P values \\
\hline Age $>60$ years & 1.956 & 1.017 to 3.762 & 0.044 & 1.476 & 0.797 to 2.732 & 0.215 \\
\hline Alcohol history & 1.768 & 0.966 to 3.237 & 0.065 & 1.281 & 0.718 to 2.284 & 0.402 \\
\hline Smoking history & 1.835 & 0.954 to 3.531 & 0.069 & 1.456 & 0.525 to 4.038 & 0.067 \\
\hline \multicolumn{7}{|l|}{ Comorbidities } \\
\hline Diabetes mellitus & 2.207 & 1.128 to 4.317 & 0.021 & 2.000 & 1.008 to 3.968 & 0.047 \\
\hline Coronary artery disease & 1.894 & 0.915 to 3.919 & 0.085 & 1.482 & 0.682 to 3.221 & 0.321 \\
\hline Peptic ulcer disease & 1.973 & 0.859 to 4.535 & 0.109 & 1.420 & 0.565 to 3.567 & 0.456 \\
\hline \multicolumn{7}{|l|}{ Tumour location (\%) } \\
\hline Junction & 1 & Reference & 0.044 & 1 & Reference & 0.154 \\
\hline \multicolumn{7}{|l|}{ Anastomotic level (\%) } \\
\hline $\mathrm{COA}$ & 1.753 & 0.974 to 3.155 & & 1.622 & 0.897 to 2.934 & \\
\hline \multicolumn{7}{|l|}{ Surgical procedure, $\%$} \\
\hline Open & 1 & Reference & 0.032 & 1 & Reference & 0.049 \\
\hline Minimally invasive & 1.863 & 1.055 to 3.290 & & 1.770 & 1.003 to 3.125 & \\
\hline \multicolumn{7}{|l|}{ Anastomotic mode, \% } \\
\hline Semimechanical & 1 & Reference & 0.024 & 1 & Reference & 0.048 \\
\hline Stapled & 2.174 & 1.070 to 4.416 & & 1.821 & 0.854 to 3.880 & \\
\hline Handsewn & 2.284 & 1.118 to 4.664 & & 2.271 & 1.055 to 4.887 & \\
\hline
\end{tabular}

COA, cervical oesophagogastric anastomosis; IOA, intrathoracic oesophagogastric anastomosis.

into multivariate logistic regression analysis to identify independent risk factors for overall anastomotic leakage as endpoint.

The results of univariate and multivariate analyses are shown in table 5, respectively. Multivariable analyses using a stepwise backward model revealed that diabetes mellitus (OR 2.001, $\mathrm{p}=0.047$ ), surgical pathway (sweet: reference; Ivor Lewis: OR 1.456; McKeown: OR 2.362, p=0.041), surgical procedure (open: reference; minimally invasive: OR 1.770, p=0.049) and anastomotic mode (semimechanical: reference; stapled: OR 1.821; handsewn: OR 2.271, $\mathrm{p}=0.048$ ) were independent predictors of leakage. Multivariate analyses revealed that the level of anastomotic site may not affect the risk for anastomotic leakage (OR 1.622; 95\% CI 0.897 to $2.934, \mathrm{p}=0.110$ ).

\section{DISCUSSION}

We performed this retrospective study to test the hypothesis that anastomotic level may affect anastomotic leakage occurrence after elective oesophagectomy. Our study revealed similar anastomotic leakage after intrathoracic anastomosis compared with cervical anastomosis. Previous studies have revealed several preoperative predictors of leakage including smoking, hypertension, renal insufficiency and albumin. ${ }^{7-10}$ In addition, we specially added all relevant operative covariates into logistic analysis to identify independent risk factors for leakage as an endpoint. Our multivariate analysis indicated that diabetes mellitus, surgical procedures and anastomotic method rather than the level of anastomotic site were all independent predictors of anastomotic leakage after oesophageal cancer surgery.

Unlike the previous reported results, ${ }^{16-18}$ we failed to identify the level of anastomotic site as an independent predictor of postoperative anastomotic leakage after adjusting for other confounding factors, although more patients in the COA group developed more anastomotic leakage than those in the IOA group. It is revealed that the level of anastomotic site may not affect the risk for anastomotic leakage. One potential explanation is the variety of definitions used for anastomotic leakage between the previous literatures and present study in which we use the definition from ECCG to grade postoperative leakage. ${ }^{15}$

Although the role of anastomotic mode in leakage after oesophagectomy has been investigated widely in recent years, results from relevant literature remain controversial. ${ }^{19}$ We found that the anastomotic mode is significantly associated with the occurrence of anastomotic leakage. It is possible that the large triangulated opening created with the stapled technique results in decreased early 
anastomotic obstruction compared with the hand-sewn technique, resulting in decreased anastomotic leakage. ${ }^{18}$ Our findings is in line with the results from Harustiak's study demonstrating the superiority of stapled to handsewn technique in leakage occurrence,${ }^{18}$ but in contrast to the earlier publications demonstrating the similar leakage rates between techniques. ${ }^{20-22}$

Our study found patients undergoing oesophagectomy with COA have higher functional morbidity than those with IOA, which is in line with Workum's recent report. ${ }^{23}$ Potential explanations are that relatively more ischaemia of the tip of the gastric tube in COA likely contributes to an increased incidence of anastomotic leakage, ${ }^{24}$ strictures $^{25}$ and dysphagia ${ }^{23}$ compared with IOA. In our study, however, IOA is associated with a higher reintervention rate than COA, which might be explained by our aggressive attitude towards treatment of intrathoracic anastomotic leakage.

Multivariable analysis in our study suggested that minimally invasive oesophagectomy increased the risk of anastomotic leakage compared with open oesophagectomy. Similar findings have been reported in the previous studies. ${ }^{3} 2627$ The most important explanation is the adverse impact of forceps grasping during laparoscopic manoeuvre on submucosalblood supply of the stomach. ${ }^{2829}$ Another explanation is that surgeon's learning curve of introducing minimally invasive oesophagectomy, ${ }^{30} 31$ even in high-volume centres, is much longer than that of introducing open oesophagectomy regardless of COA or IOA.

\section{Strengths and limitations}

The strength of this study is the focus on surgical and anastomotic techniques, the consecutive design and the comparison of a large cohort of patients treated after COA and IOA. There are several limitations in our study that should be mentioned when interpreting our results. First, our study is subject to inherent biases given the retrospective design. Although these preoperative variables between groups were equally distributed, we could not entirely exclude all relevant confounding factors in clinical practice that might influence our results. Second, we only included anastomotic leakage which was indicated explicitly in our medical records rather than evaluate minor leakages as they were uncertain and difficult to diagnose. Third, the findings should be generalised carefully as they were based on a single hospital of traditional Chinese medicine. Also, because surgical invasiveness is completely different between the thoracic anastomosis, so it is necessary to compare the prognosis in addition to short-term postoperative outcomes in the future study.

\section{CONCLUSIONS}

COA was associated with comparable anastomotic morbidity compared with IOA in this study. Surgical and anastomotic techniques rather than the level of anastomotic site were independent predictors of postoperative anastomotic leakage in patients undergoing oesophageal cancer surgery. A randomised controlled trial is warranted to investigate whether these findings can be confirmed prospectively.

Contributors YL and SZ contributed to the conception and design of the study. YL, $\mathrm{SZ}$ and $\mathrm{RC}$ participated in the data acquisition. YL, JF, HH, SZ and QC contributed to the drafting or revising of the manuscript. All the authors gave their approval for the final version of the manuscript.

Funding The authors have not declared a specific grant for this research from any funding agency in the public, commercial or not-for-profit sectors.

Competing interests None declared.

Patient consent Obtained.

Ethics approval Approval was obtained to review the data from Institutional Ethical Committee of Taizhou City Hospital of Traditional Chinese Medicine.

Provenance and peer review Not commissioned; externally peer reviewed.

Data sharing statement No additional data are available.

Open access This is an open access article distributed in accordance with the Creative Commons Attribution Non Commercial (CC BY-NC 4.0) license, which permits others to distribute, remix, adapt, build upon this work non-commercially, and license their derivative works on different terms, provided the original work is properly cited, appropriate credit is given, any changes made indicated, and the use is non-commercial. See: http://creativecommons.org/licenses/by-nc/4.0/.

\section{REFERENCES}

1. Chen W, Zheng R, Baade PD, et al. Cancer statistics in China, 2015. CA Cancer J Clin 2016;66:115-32.

2. Stahl M, Mariette $\mathrm{C}$, Haustermans $\mathrm{K}$, et al. Oesophageal cancer: ESMO clinical practice guidelines for diagnosis, treatment and follow-up. Ann Oncol 2013;24:iv68-70.

3. Kassis ES, Kosinski AS, Ross P, et al. Predictors of anastomotic leak after esophagectomy: an analysis of the society of thoracic surgeons general thoracic database. Ann Thorac Surg 2013;96:1919-26.

4. Shah SP, Xu T, Hooker CM, et al. Why are patients being readmitted after surgery for esophageal cancer? J Thorac Cardiovasc Surg 2015;149:1384-91.

5. Markar S, Gronnier C, Duhamel A, et al. The impact of severe anastomotic leak on long-term survival and cancer recurrence after surgical resection for esophageal malignancy. Ann Surg 2015;262:972-80.

6. Biere SS, Maas KW, Cuesta MA, et al. Cervical or thoracic anastomosis after esophagectomy for cancer: a systematic review and meta-analysis. Dig Surg 2011;28:29-35.

7. Markar SR, Arya S, Karthikesalingam A, et al. Technical factors that affect anastomotic integrity following esophagectomy: systematic review and meta-analysis. Ann Surg Oncol 2013;20:4274-81.

8. Van Daele E, Van de Putte D, Ceelen W, et al. Risk factors and consequences of anastomotic leakage after Ivor Lewis oesophagectomy. Interact Cardiovasc Thorac Surg 2016;22:32-7.

9. Goense L, van Rossum PS, Tromp M, et al. Intraoperative and postoperative risk factors for anastomotic leakage and pneumonia after esophagectomy for cancer. Dis Esophagus 2017;30:1-10.

10. Pennathur A, Gibson MK, Jobe BA, et al. Oesophageal carcinoma. Lancet 2013;381:400-12.

11. Wajed SA, Veeramootoo D, Shore AC. Video. Surgical optimisation of the gastric conduit for minimally invasive oesophagectomy. Surg Endosc 2012;26:271-6.

12. Tanaka K, Makino T, Yamasaki M, et al. An analysis of the risk factors of anastomotic stricture after esophagectomy. Surg Today 2018;48:449-54.

13. Li SJ, Wang ZQ, Li YJ, et al. Diabetes mellitus and risk of anastomotic leakage after esophagectomy: a systematic review and meta-analysis. Dis Esophagus 2017;30:30.

14. Sobin L, Gospodarowicz M, Wittekind C. TNM classification of malignant tumors. 7th edn. Oxford: Wiley-Blackwell, 2010.

15. Harustiak T, Pazdro A, Snajdauf M, et al. Anastomotic leak and stricture after hand-sewn versus linear-stapled intrathoracic oesophagogastric anastomosis: single-centre analysis of 415 oesophagectomies. Eur J Cardiothorac Surg 2016;49:1650-9. 
16. Low DE, Alderson D, Cecconello I, et al. International consensus on standardization of data collection for complications associated with esophagectomy: Esophagectomy Complications Consensus Group (ECCG). Ann Surg 2015;262:286-94.

17. Klink CD, Binnebösel M, Otto J, et al. Intrathoracic versus cervical anastomosis after resection of esophageal cancer: a matched pair analysis of 72 patients in a single center study. World J Surg Oncol 2012;10:159-5.

18. Huang HT, Wang F, Shen L, et al. Clinical Outcome of middle thoracic esophageal cancer with intrathoracic or cervical anastomosis. Thorac Cardiovasc Surg 2015;63:328-34

19. Deng XF, Liu QX, Zhou D, et al. Hand-sewn vs linearly stapled esophagogastric anastomosis for esophageal cancer: a metaanalysis. World J Gastroenterol 2015;21:4757-64.

20. Price TN, Nichols FC, Harmsen WS, et al. A comprehensive review of anastomotic technique in 432 esophagectomies. Ann Thorac Surg 2013;95:1154-61.

21. Blackmon SH, Correa AM, Wynn B, et al. Propensity-matched analysis of three techniques for intrathoracic esophagogastric anastomosis. Ann Thorac Surg 2007;83:1805-13.

22. Castro PM, Ribeiro FP, Rocha AF, et al. Hand-sewn versus stapler esophagogastric anastomosis after esophageal ressection: systematic review and meta-analysis. Arq Bras Cir Dig 2014;27:216-21.

23. van Workum F, van der Maas J, van den Wildenberg FJ, et al. Improved functional results after minimally invasive esophagectomy: intrathoracic versus cervical anastomosis. Ann Thorac Surg 2017;103:267-73.

24. Urschel JD. Esophagogastrostomy anastomotic leaks complicating esophagectomy: a review. Am J Surg 1995;169:634-40.

25. Pierie JP, de Graaf PW, Poen $\mathrm{H}$, et al. Incidence and management of benign anastomotic stricture after cervical oesophagogastrostomy. Br J Surg 1993;80:471-4.

26. Mao T, Fang W, Gu Z, et al. Comparison of perioperative outcomes between open and minimally invasive esophagectomy for esophageal cancer. Thorac Cancer 2015;6:303-6.

27. Yamamoto S, Kawahara K, Maekawa T, et al. Minimally invasive esophagectomy for stage I and II esophageal cancer. Ann Thorac Surg 2005;80:2070-5

28. Ben-David K, Sarosi GA, Cendan JC, et al. Decreasing morbidity and mortality in 100 consecutive minimally invasive esophagectomies. Surg Endosc 2012;26:162-7.

29. Nguyen NT, Rudersdorf PD, Smith BR, et al. Management of gastrointestinal leaks after minimally invasive esophagectomy: conventional treatments vs. endoscopic stenting. J Gastrointest Surg 2011;15:1952-60.

30. Tapias LF, Morse CR. Minimally invasive Ivor Lewis esophagectomy: description of a learning curve. J Am Coll Surg 2014;218:1130-40.

31. van Workum F, van den Wildenberg FJ, Polat F, et al. Minimally invasive oesophagectomy: preliminary results after introduction of an intrathoracic anastomosis. Dig Surg 2014;31:95-103. 